\title{
A DESIGUALDADE SALARIAL NO SETOR FLORESTAL BRASILEIRO
}

\author{
Wage Gap Within the Brazilian Forest Sector
}

\begin{abstract}
RESUMO
O setor florestal brasileiro gerou, em 2018, cerca de 3,8 milhões de empregos diretos e indiretos. Dada a importância do setor para a economia brasileira, objetivou-se analisar a existência de discriminação salarial por gênero e raça/cor no setor no mercado de trabalho, aplicando a metodologia de decomposição de Oaxaca-Blinder. Para a construção das variáveis, utilizaram-se dados secundários extraídos da Pesquisa Nacional por Amostra de Domicílios (PNAD), elaborada pelo Instituto Brasileiro de Geografia e Estatística - IBGE, do ano de 2015, e utilizou-se o programa de estatística Stata 14 para fazer as análises. Foram analisados os ramos agrícola e industrial, a fim de observar em qual deles existe maior discriminação salarial entre homens e mulheres, e entre brancos e não brancos. Observou-se que existem evidências de uma possível discriminação de gênero e de cor/raça no setor florestal brasileiro como um todo. No entanto, há evidências de que a diferença no retorno das características produtivas seja bem mais significativa na análise por gênero, principalmente no ramo industrial $(169,6 \%)$. $\mathrm{Na}$ análise por raça/cor, o efeito característica se sobrepôs ao efeito preço na explicação do diferencial total de rendimentos.
\end{abstract}

Renata da Costa Pereira

Universidade Federal da Grande Dourados

renatta-pereira@hotmail.com

Jaqueline Severino Costa

Universidade Federal de Lavras

jaqueline.s.costa@ufla.br

Pedro Rodrigues de Oliveira

Universidade Federal da Grande Dourados

pedrorodrigues@ufgd.edu.br

Juliana Maria de Aquino

Universidade Federal da Grande Dourados

julianaaquino@ufgd.edu.br

Recebido em: 10/04/2020. Aprovado em: 24/03/2021.

Avaliado pelo sistema double-blind review

Avaliador científico: Elisa Reis Guimarães

DOI: $10.48142 / 2320211633$

\begin{abstract}
In 2018, the Brazilian forest sector supported about 3.8 million direct and indirect jobs. Considering the importance of the sector for the Brazilian economy, this paper addresses the existence of gender and race/color wage discrimination in the labor market within the sector through Oaxaca-Blinder decomposition. Data was drawn from the 2015 national households survey PNAD and analyzed through the Stata 14 software. Both the agricultural and industrial branches of the sector were analyzed in separate, with evidences of a possible discrimination being found on the sector as a whole. We found that the gender returns' difference in productive characteristics is stronger within the industrial branch (169.9\%). However, when analyzing the color/race difference, the characteristics effect outweighed the price effect on explaining the earnings gap.
\end{abstract}

Palavras-chave: Decomposição de Oaxaca-Blinder; Gênero; Raça.

Keywords: Oaxaca-Blinder Decomposition; Gender; Race.

\section{INTRODUÇÃO}

O setor florestal possui grande relevância para a economia brasileira. Sua competitividade tem origem nos mais diversos fatores, como o clima favorável, a utilização de biotecnologia e engenharia genética, e o baixo custo de produção da celulose (Departamento de Pesquisas e Estudos Econômicos [DEPEC], 2018).

O país produziu 297,37 milhões de metros cúbicos de madeira em 9 milhões de hectares de florestas plantadas em 2019. No mesmo ano, o total exportado foi de US\$ 11,3 bilhões, contribuindo para um saldo na balança comercial de cerca de US\$10,3 bilhões. Além disso, o setor de florestas plantadas gerou uma receita tributária para o Brasil de cerca de $\mathrm{R} \$ 13$ bilhões, o que corresponde a $0,9 \%$ da arrecadação total do país. Este setor manteve de forma direta, em 2019, cerca de 1,3 milhão de empregos (Indústria Brasileira de Árvores [IBÁ], 2020).

No ano de 2020, a produção nacional de celulose foi de 21 milhões de toneladas, sendo que destas, 15,6 
milhões de toneladas foram destinadas à exportação, correspondendo a aproximadamente $74,3 \%$ da produção total do País (IBÁ, 2020).

A Organização Internacional do Trabalho (OIT), em sua declaração sobre os Princípios e Direitos do Trabalho, aponta que o trabalho decente é essencial para a superação da pobreza e para a manutenção da governabilidade democrática, de modo a reduzir as desigualdades sociais e garantir o desenvolvimento sustentável. Nesse contexto, surge o conceito de trabalho decente que almeja a promoção de igualdade de oportunidades no mercado de trabalho para homens/mulheres e brancos/não brancos, e que considere a dignidade humana, a segurança, a liberdade e a equidade (OIT, 2018).

Contudo, o desenvolvimento sustentável não alcançou a sua plenitude, uma vez que questões como desigualdades salariais em função de gênero e cor/raça, ainda não foram superados no mundo do trabalho. A discriminação é um fator que contribui para a existência de desigualdade salarial e tem como consequências a instabilidade política, o baixo desenvolvimento socioeconômico, a baixa produtividade, baixa competitividade, e a ampliação do ciclo da pobreza (OIT, 1999).

Em razão da importância econômica e social do setor florestal para a economia brasileira, este trabalho tem como objetivo analisar a existência de discriminação salarial de gênero e raça/cor, mais especificamente entre as áreas agrícola e industrial deste setor.

$\mathrm{O}$ procedimento metodológico utilizado neste trabalho foi a decomposição de Oaxaca-Blinder e visa explicar as diferenças salariais no mercado de trabalho no setor de papel e celulose. Oaxaca (1973) argumenta que sempre que os salários dos homens excederem os salários das mulheres, considerando as mesmas características produtivas, haverá discriminação com relação ao trabalho feminino.

Embora a metodologia de Oaxaca (1973) seja amplamente utilizada na literatura, a sua aplicação no setor de papel e celulose pode ser útil aos gestores públicos na medida em que os resultados encontrados possam ser utilizados na elaboração de políticas públicas focalizadas para mitigar ou eliminar as distorções salariais de gênero e raça ou cor no setor florestal brasileiro.

Ademais, os resultados podem ser úteis às empresas do setor florestal com o objetivo de atingir processos de produção mais sustentáveis em consonância com os 17 objetivos de desenvolvimento sustentável, particularmente no que se referem aos objetivos 5 e 10 que versam sobre a igualdade de gênero e redução das desigualdades, respectivamente (Organização das Nações Unidas [ONU], 2014).

\section{REVISÃO BIBLIOGRÁFICA}

As mulheres continuam sendo discriminadas em praticamente todas as faces do emprego, desde o acesso a oportunidades e remuneração salarial até as promoções em cargos de liderança. As leis e medidas legais elaboradas para diminuir a discriminação de gênero e aumentar o acesso de mulheres ao mercado de trabalho são relevantes para a formação de uma sociedade mais justa e igualitária (OIT, 2011).

Gênero e a raça/cor são fatores determinantes para o acesso às melhores posições e condições de remuneração e aos benefícios no mercado. Essas características individuais estão amplamente correlacionadas à vulnerabilidade socioeconômica a que estes indivíduos estão expostos, sendo um obstáculo para a superação da pobreza e extrema pobreza (OIT, 2019).

Neste contexto, vários autores argumentam que, quando indivíduos igualmente produtivos auferem remunerações salariais diferentes em decorrência de seu gênero ou raça/cor, pode haver indícios de discriminação no mercado de trabalho (Oaxaca, 1973; Coleman, 2003; Giuberti \& Menezes-Filho, 2005; Böheim, Himpele, Mahringer \& Zulehner, 2013; Grandner \& Gstach, 2015).

As diferenças de rendimentos salariais entre homens e mulheres existentes entre o Brasil e os Estados Unidos foram comparadas nos anos de 1981, 1988 e 1996. Os resultados mostraram que, no Brasil, o retorno médio salarial das mulheres equivale a $68 \%$ do retorno masculino em 1981, e em 1996 era o equivalente a 80\% do rendimento masculino. Já nos Estados Unidos, o rendimento salarial feminino equivalia a $66 \%$ do rendimento masculino em 1981, passando para 78\% em 1996. Em ambos os períodos e países analisados, a diferença salarial sempre foi em favor dos homens. Os autores concluíram que realmente existem diferenças salariais entre homens e mulheres que não são explicadas por características individuais como escolaridade, idade e experiência laboral (Giuberti \& Menezes-Filho, 2005). Em um estudo na Áustria, foi evidenciado que cerca de $60 \%$ da desigualdade salarial existente entre homens e mulheres não são explicados pelas diferentes características individuais de produtividade. $\mathrm{O}$ estudo concluiu que as mulheres austríacas auferem um rendimento salarial $11 \%$ menor ao dos homens (Böheim et al., 2013). 
Pesquisas conduzidas na Alemanha e na Áustria buscaram analisar a diferença salarial entre homens e mulheres em 2008 e quantificar as características explicativas que influenciam na formação do salário. Os resultados mostraram que, na Alemanha, as diferenças salariais persistentes encontradas variam de 20 a $25 \%$, favorável aos homens em relação às mulheres, sendo que 15 pontos percentuais são exclusivamente na forma de discriminação contra as mulheres. Diferentes características, como escolaridade, experiência e idade, por outro lado, podem explicar de 5 a 10 pontos percentuais. $\mathrm{Na}$ Áustria, estimou-se uma vantagem salarial para os homens em cerca de $20 \%$ acima dos valores auferidos pelas mulheres. Contudo, diferentemente da Alemanha, na Áustria não há diferença salariais decorrentes das características individuais dos trabalhadores (Grandner \& Gstach, 2015).

No cenário brasileiro, autores como Batista e Cacciamali (2009), Cirino e De Lima (2012), De Souza, Maia, Fiuza-Moura, Gomes \& Silva (2015), Mattei e Baço (2017) e Fonseca, Bacchi, Catelan, Hayashi \& Maia (2017) analisaram as diferenças salariais entre trabalhadores brasileiros. Batista e Cacciamali (2009) estudaram o diferencial de salários entre homens e mulheres segundo a sua condição de migração, utilizando o cálculo do índice de dissimilaridade de Duncan e a decomposição de Oaxaca-Blinder. Eles constataram a existência de dois casos: no primeiro, tem-se a região Sudeste, onde a diferença de rendimentos por gênero é menor entre os indivíduos migrantes do que entre os não migrantes; no segundo caso, nota-se que a diferença de rendimentos por gênero no restante do país é menor entre os indivíduos não migrantes que entre os migrantes.

Foi elaborado um estudo que visava comparar a diferença salarial entre os trabalhadores da Região Metropolitana de Salvador (RMS) e da Região Metropolitana de Belo Horizonte (RMBH), no ano de 2006. A conclusão do estudo aponta que, na RMBH, os rendimentos do trabalho são maiores que os observados na RMS, tanto para os homens, quanto para as mulheres (Cirino \& De Lima, 2012)

As diferenças salariais e o impacto da discriminação por gênero e cor no mercado de trabalho brasileiro foram mensuradas por De Souza et al. (2015), a partir dos dados da PNAD 2013. Os resultados mostraram que o hiato salarial é desfavorável aos trabalhadores do gênero feminino, sendo que as características produtivas, como educação e experiência, e as ocupações são os fatores mais importantes para a diminuição dessas diferenças salariais. Por fim, os autores sugerem que as características estudadas dos indivíduos explicam apenas um quarto das diferenças salariais existentes e que a discriminação de gênero e cor explicam os outros três quartos restantes.

As diferenças salariais existentes no mercado de trabalho do estado de Santa Catarina nos anos 2000, 2007 e 2014 foram estudadas por Mattei e Baço (2016). Utilizou-se o método de decomposição de rendimentos de Oaxaca-Blinder, de modo a analisar os dados da Relação Anual de Informações Sociais - RAIS. Observou-se que as diferenças salariais entre os homens e as mulheres diminuíram no período analisado no estado, logo a discriminação no mercado de trabalho contra as mulheres, que é a principal causa dessa diferença salarial, também diminuiu no período considerado.

Mais recentemente, Fonseca et al. (2017) analisaram a discriminação salarial de gênero e cor de pele na região Norte do Brasil em 2004 e 2013. Para estimar as equações de determinação salarial e verificar a existência de discriminação no mercado de trabalho foram utilizados os dados da Pesquisa Nacional por Amostra de Domicílios (PNAD) com aplicação da metodologia de decomposição de Oaxaca-Blinder. O estudo concluiu que, apesar do grau de discriminação por gênero e cor ter reduzido no período analisado, a desigualdade salarial permaneceu e o principal responsável por isso é o fator discriminatório, presente no mercado de trabalho da região Norte.

Sobre a discriminação salarial em setores específicos, Jacinto (2005) analisou a indústria avícola da região sul do Brasil; Bonini e Pozzobon (2016) estudaram as indústrias de transformação e de informação e comunicação, da região sul brasileira; e Mattei e Baço (2016) analisaram a indústria de transformação do estado de Santa Catarina.

Ao analisar os diferenciais de salários por gênero na indústria avícola da região Sul do Brasil, Jacinto (2005) utilizou como base de dados a RAIS de 1998. Desta forma, utilizou-se a decomposição de Oaxaca (1973) para mensurar as diferenças de salários entre trabalhadores semelhantes quanto à educação e ocupação. Os resultados obtidos apontaram a existência de diferenças salariais favoráveis ao gênero masculino.

O salário, a produtividade e o gênero dos trabalhadores nas indústrias de transformação e de informação e comunicação, da região Sul brasileira, foi estudado por Bonini e Pozzobon (2016). Utilizou-se a base de dados da RAIS, de 2011, e aplicou-se uma metodologia baseada na economia da discriminação e no método de decomposição de Oaxaca. Os resultados sugeriram a 
existência de discriminação salarial feminina nos estados do Paraná, Santa Catarina e Rio Grande do Sul.

Por fim, a existência da diferença salarial entre os homens e as mulheres na indústria de transformação do estado de Santa Catarina, e se essa diferença pode ser atribuída à discriminação foram estimados por Mattei e Baço (2017). Utilizou-se o método de decomposição de rendimentos de Oaxaca-Blinder, para analisar os dados oriundos da base de dados da RAIS, para o ano de 2012. Os resultados obtidos apontaram a existência da diferença salarial a favor dos homens e sugeriram, também, que a maior parte desta diferença é atribuída a fatores não explicados pelos atributos dos trabalhadores, o que pode indicar a existência de discriminação no setor de transformação.

No Quadro 1, apresenta-se um resumo das principais contribuições da literatura supracitada sobre $o$ tema de discriminação de gênero e cor/raça no mercado de trabalho brasileiro, considerando diferentes períodos e setores da economia.

$\mathrm{Na}$ maioria dos estudos analisados, são recorrentes os indícios de discriminação de gênero e raça nos mais diversos setores da economia brasileira. Diante dessas evidências, o presente estudo foca a análise no setor florestal brasileiro, de modo a observar a possível existência de discriminação no mercado de trabalho, uma vez que estudos que analisem aspectos relacionados à discriminação de gênero à cor/raça carecem de maior aprofundamento. Deste modo, este estudo visa robustecer a literatura com informações qualificadas sobre este setor tão relevante para a economia brasileira.

\section{CARACTERIZAÇÃO DO SETOR FLORESTAL BRASILEIRO}

O setor florestal representa uma cadeia produtiva relevante para a economia mundial, pois se constitui em um fornecedor de insumos para o setor de energia e de matérias primas para a construção civil e para a indústria de transformação (Sistema Nacional de Informações Florestais [SNIF], 2020).

A cadeia produtiva do setor florestal brasileiro apresenta uma atividade econômica complexa e com diversidade de produtos. Esta complexidade pode ser observada na medida em que o país divide o setor em produtos florestais madeireiros e não madeireiros, mas também em florestas nativas e florestas plantadas (Figura 1).
A competitividade brasileira no setor florestal pode ser atribuída a diversos fatores, como o clima favorável, a utilização de biotecnologia e engenharia genética, e o baixo custo de produção da celulose (DEPEC, 2018).

No setor madeireiro, os tipos de fibras mais cultivadas no Brasil são a fibra longa, oriunda do Pinus, $e$ a fibra curta, originária do eucalipto. A fibra longa destina-se à fabricação de produtos mais rígidos, como embalagens. Já a fibra curta é utilizada na produção de papéis com menor rigidez, como papéis para impressão, para escrever e papéis tissue (higiênicos) (DEPEC, 2018). No setor chamado não madeireiro, existem outras fibras oriundas do bambu, o sisal, o babaçu, e resíduos agrícolas, como o bagaço de cana de açúcar, entre outros (IBÁ, 2018).

O eucalipto pode ser cortado em média com sete anos, já o Pinus leva em torno de 15 a 20 anos para atingir a maturidade para corte (DEPEC, 2018). Quando as florestas atingem a idade adequada, elas são cortadas e a madeira é transportada até as fábricas de transformação. $\mathrm{Na}$ sequência, são descascadas, lavadas e picadas em pequenos pedaços e encaminhadas para a próxima etapa, a de formação da polpa, branqueamento e secagem. Após esse processo, são feitos fardos de celulose e enviados para as fábricas de papel (Associação Mineira do Meio Ambiente [AMDA], 2018).

Com o menor ciclo de vida da planta, ocorre um predomínio de área total de florestas plantadas de Eucalipto, embora possa se observar o crescimento de área plantada de Eucalipto e Pinus (Figura 2).

$\mathrm{Na}$ Figura 3, apresenta-se a evolução da produtividade média de Eucalipto (acima de $35 \mathrm{~m}^{3} / \mathrm{ha}$ ano) e de Pinus (acima de $30 \mathrm{~m}^{3} / \mathrm{ha} / \mathrm{ano}$ ). As oscilações de baixa refletem as mudanças climáticas, como períodos de veranicos, bem como expansão de áreas novas, fatores bióticos e abióticos (IBÁ, 2020).

Observa-se que grande parte das florestas plantadas teve como destino a produção de celulose e papel. Na Figura 4, é possível verificar que a produção de celulose foi o setor que mais cresceu no período e atingiu um pico de crescimento em 2018, com 21 milhões de toneladas. Com relação à produção de papel, esta alcançou uma média superior aos 10 milhões de toneladas.

Grande parte da produção de papel brasileiro tem como destino as exportações, o que é refletido pelo desempenho favorável da Balança Comercial. Embora a economia brasileira tenha necessidade de importar, o comércio exterior de papel tem sido favorável ao Brasil, se comparado ao resto do mundo (Figura 5). 
QUADRO 1 - Resumo da literatura utilizada na revisão bibliográfica deste estudo

\begin{tabular}{|c|c|c|}
\hline Autores & Objetivo & Conclusões \\
\hline $\begin{array}{l}\text { Giuberti e Menezes-Filho } \\
\qquad(2005)\end{array}$ & $\begin{array}{l}\text { Comparar os rendimentos salariais entre } \\
\text { homens e mulheres no Brasil e nos Estados } \\
\text { Unidos em diferentes anos. }\end{array}$ & $\begin{array}{l}\text { Existem diferenças salariais entre homens } \\
\text { e mulheres que não são explicadas por } \\
\text { características individuais, como escolaridade, } \\
\text { idade e experiência laboral. }\end{array}$ \\
\hline Böheim et al. (2013) & $\begin{array}{l}\text { Comparar a existência de diferença salarial } \\
\text { entre homens e mulheres na Áustria. }\end{array}$ & $\begin{array}{l}\text { As mulheres austríacas ganham, em média, } \\
11 \% \text { a menos que os homens. }\end{array}$ \\
\hline Grandner e Gstach (2015) & $\begin{array}{l}\text { Analisar a diferença salarial entre homens e } \\
\text { mulheres na Alemanha e na Áustria. }\end{array}$ & $\begin{array}{l}\text { Existem diferenças salariais de } 20 \% \text { a } 25 \% \\
\text { favoráveis aos homens, das quais } 15 \% \\
\text { se referem à discriminação e o restante a } \\
\text { diferenças nas características individuais. }\end{array}$ \\
\hline Batista e Cacciamali (2009) & $\begin{array}{l}\text { Analisar as diferenças salariais entre homens } \\
\text { e mulheres no mercado de trabalho brasileiro, } \\
\text { segundo a condição de imigração. }\end{array}$ & $\begin{array}{l}\text { Na região Sudeste, o rendimento salarial por } \\
\text { gênero é menor entre os indivíduos migrantes } \\
\text { que entre os não migrantes. No restante do } \\
\text { Brasil, a diferença salarial por gênero é menor } \\
\text { entre os indivíduos não migrantes do que entre } \\
\text { os migrantes. }\end{array}$ \\
\hline Cirino e De Lima (2012) & $\begin{array}{l}\text { Comparar a diferença salarial de homens e } \\
\text { mulheres entre as regiões metropolitanas de } \\
\text { Belo Horizonte e de Salvador. }\end{array}$ & $\begin{array}{l}\text { Na RMBH, os rendimentos do trabalho são } \\
\text { maiores do que os observados na RMS, tanto } \\
\text { para os homens, quanto para as mulheres. }\end{array}$ \\
\hline De Souza et al. (2015) & $\begin{array}{c}\text { Analisar as diferenças salariais e o impacto da } \\
\text { discriminação, por gênero e cor, no mercado de } \\
\text { trabalho brasileiro. }\end{array}$ & $\begin{array}{c}\text { Os rendimentos salariais de mulheres } \\
\text { são menores se comparados aos valores } \\
\text { dos homens, controlando para todas as } \\
\text { características individuais, como escolaridade e } \\
\text { experiência. }\end{array}$ \\
\hline Mattei e Baço (2017) & $\begin{array}{l}\text { Estimar as diferenças salariais entre homens e } \\
\text { mulheres no estado de Santa Catarina, nos anos } \\
\text { de } 2000,2007 \text { e } 2014 \text {. }\end{array}$ & $\begin{array}{l}\text { As diferenças salariais entre os homens e } \\
\text { mulheres diminuíram no período analisado. } \\
\text { Isso significa que a discriminação contra as } \\
\text { mulheres, no que se refere à diferença salarial, } \\
\text { também diminuiu. }\end{array}$ \\
\hline Fonseca et al. (2017) & $\begin{array}{l}\text { Analisar a existência de discriminação salarial } \\
\text { de gênero e cor/raça na região Norte do Brasil. }\end{array}$ & $\begin{array}{l}\text { Apesar do grau de discriminação por gênero } \\
\text { e cor ter reduzido nos anos analisados, a } \\
\text { desigualdade salarial permaneceu e o principal } \\
\text { responsável por isso foi o fator discriminatório, } \\
\text { presente no mercado de trabalho da região } \\
\text { Norte. }\end{array}$ \\
\hline Jacinto (2005) & $\begin{array}{l}\text { Analisar as diferenças salariais por gênero na } \\
\text { indústria avícola da região Sul do Brasil. }\end{array}$ & $\begin{array}{c}\text { Existem diferenças salariais favoráveis ao } \\
\text { gênero masculino na indústria avícola na região } \\
\text { Sul. }\end{array}$ \\
\hline Bonini e Pozzobon (2016) & $\begin{array}{l}\text { Verificar as diferenças salariais entre homens } \\
\text { e mulheres na indústria de transformação da } \\
\text { região Sul do Brasil. }\end{array}$ & $\begin{array}{l}\text { Existe discriminação salarial com relação às } \\
\text { mulheres em todos os estados da região Sul do } \\
\text { Brasil. }\end{array}$ \\
\hline Mattei e Baço (2016) & $\begin{array}{l}\text { Observar a existência da diferença salarial } \\
\text { entre os homens e as mulheres na indústria de } \\
\text { transformação do estado de Santa Catarina. }\end{array}$ & $\begin{array}{l}\text { Existência da diferença salarial a favor } \\
\text { dos homens, cuja maior parte é atribuída a } \\
\text { fatores não explicados pelos atributos dos } \\
\text { trabalhadores, o que pode indicar a existência } \\
\text { de discriminação no setor de transformação. }\end{array}$ \\
\hline
\end{tabular}

Fonte: Elaborado pelos autores 


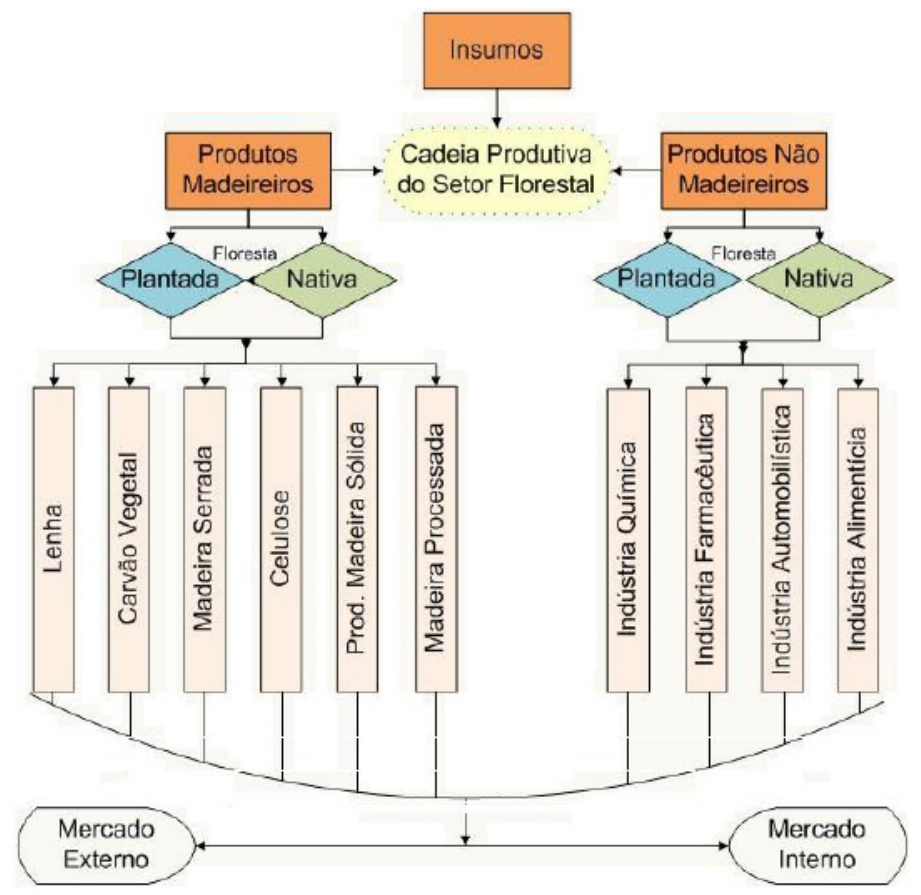

FIGURA 1 - Cadeia produtiva do setor florestal brasileiro

Fonte: Sistema Nacional de Informações Florestais - SNIF (2020, online)

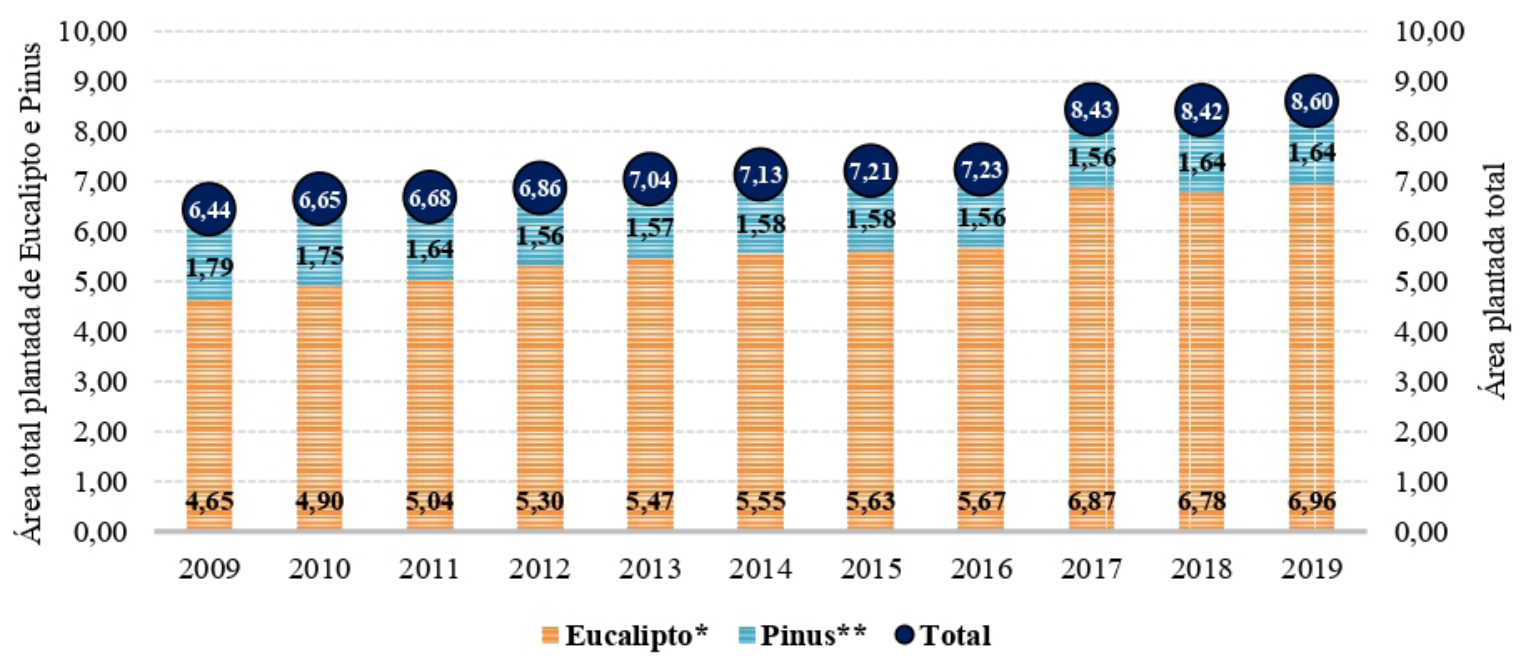

FIGURA 2 - Área plantada de Eucalipto e Pinus no Brasil, considerando os cinco principais estados produtores (em milhões de hectares)

Fonte: Elaborado pelos autores, com base nos dados da IBÁ (2014-2019). *Estados de MG, MS, SP, BA, RS, PR. ** Estados de PR, SC, RS, SP, MG e outros

A cadeia produtiva do setor florestal comercial brasileiro, em 2019 , contribuiu com $1,2 \%$ do produto interno bruto (PIB). Desse total, 46,5\% devem-se ao setor de fabricação de celulose, papel e produto de papel; $36,2 \%$ devem-se à produção florestal e $17,3 \%$ à fabricação de produtos de madeira. Esse setor foi responsável por uma 


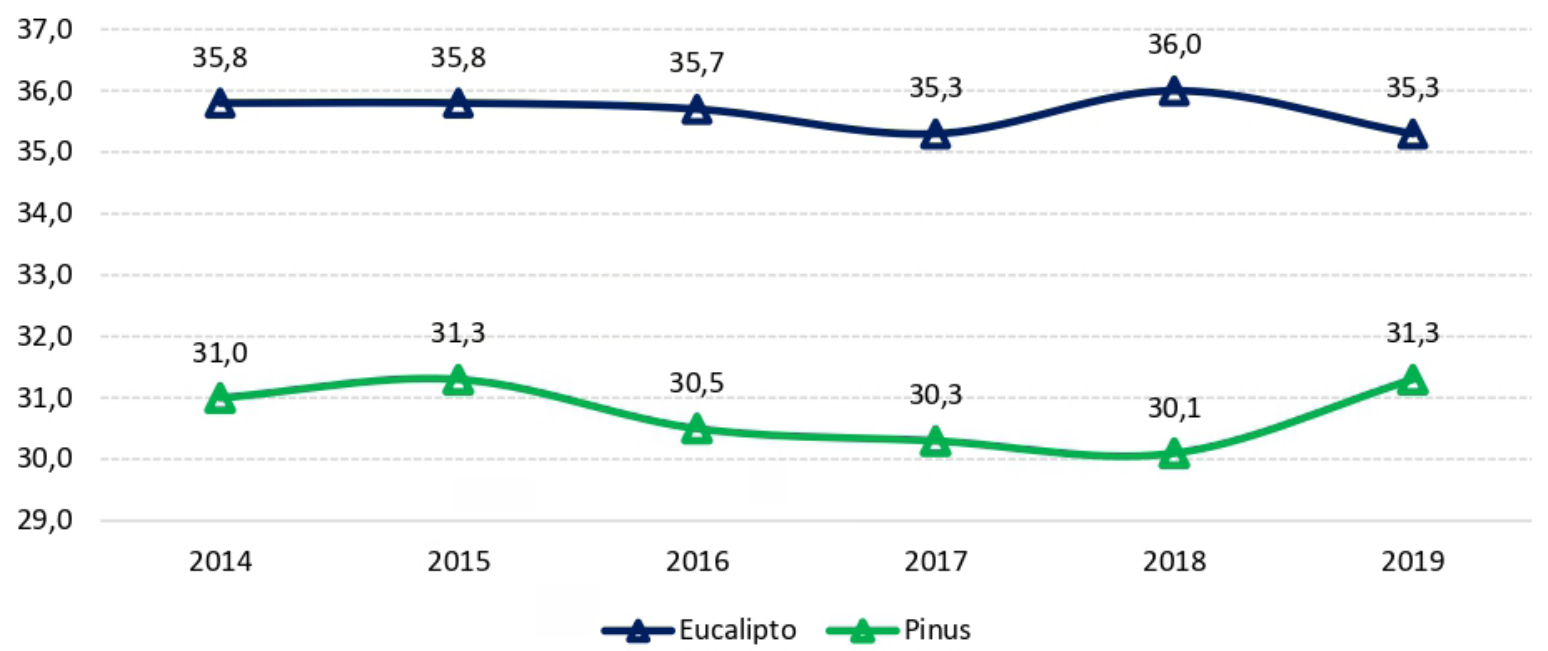

FIGURA 3 - Produtividade de Eucalipto e Pinus no Brasil (em m3/ha/ano)

Fonte: Elaborado pelos autores, com base nos dados da IBÁ (2014-2019)

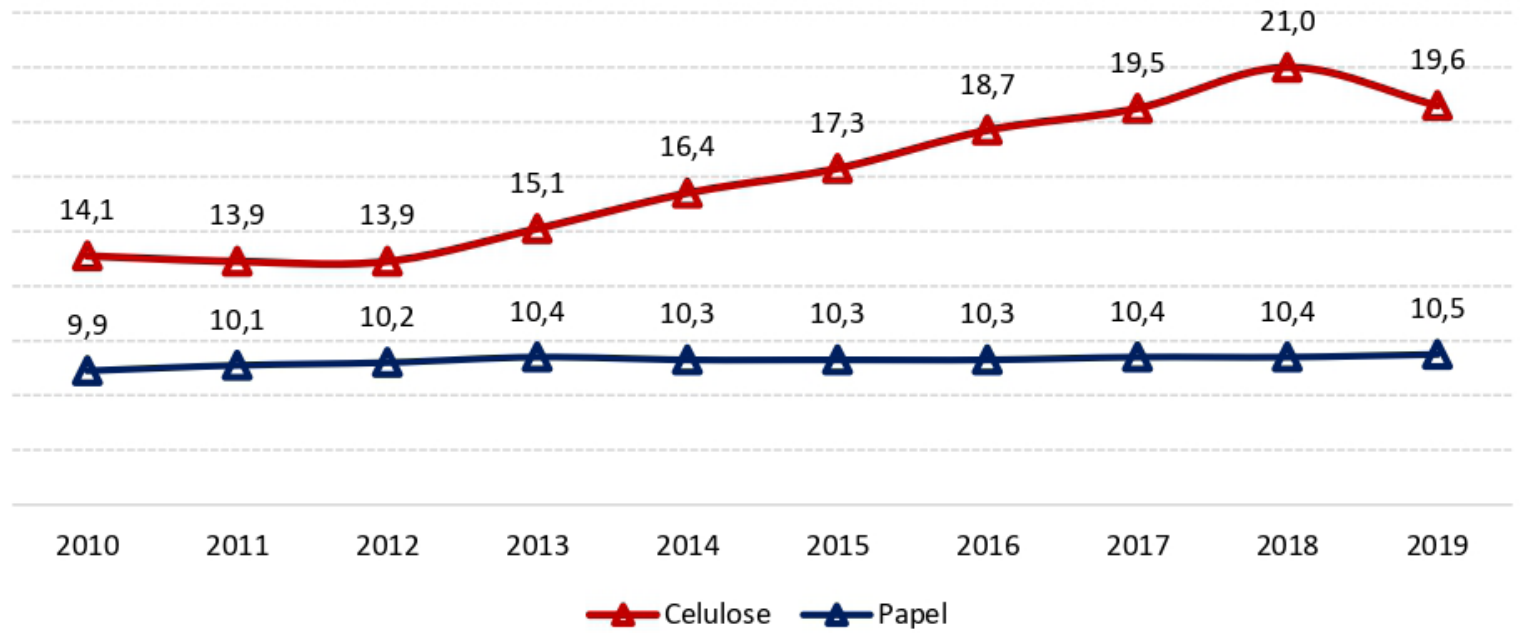

FIGURA 4 - Produção de Celulose e Papel no Brasil (em milhões de toneladas)

Fonte: Elaborado com base nos dados da IBÀ (2010-2019)

receita bruta total da ordem de $\mathrm{R} \$ 97,4$ bilhões, além de 3,75 milhões de empregos e R $\$ 13$ bilhões de arrecadação, o equivalente a $0,9 \%$ da arrecadação tributária brasileira (IBÁ, 2020).

\section{PROCEDIMENTOS METODOLÓGICOS}

\subsection{Fonte de dados}

Para a construção das variáveis do modelo, serão utilizados dados secundários extraídos da
Pesquisa Nacional por Amostra de Domicílios (PNAD), elaborada pelo Instituto Brasileiro de Geografia e Estatística - IBGE, do ano de $2015^{1}$. Os dados referentes ao setor florestal brasileiro,

${ }^{1}$ No ano de 2016, foi divulgada a PNAD referente ao ano de 2015 . Esta $P N A D$ refere-se à última divulgada com base na metodologia antiga. Até esse ano a cobertura da PNAD era feita de forma anualizada. A partir de 2016, a PNAD foi substituída, com metodologia atualizada, pela Pesquisa Nacional por Amostra de Domicílios Contínua - PNAD Contínua. A nova pesquisa disponibiliza informações conjunturais trimestrais sobre a força de trabalho em âmbito nacional. Nesse sentido, optou-se por utilizar a base anualizada no formato tradicional da PNAD. 
abrangendo todas as regiões brasileiras, foram extraídos utilizando o pacote estatístico Stata 14 (Quadro 2).
O código da atividade principal do empreendimento no trabalho principal da semana de referência será identificado pela variável V9907 da PNAD (2015). Os

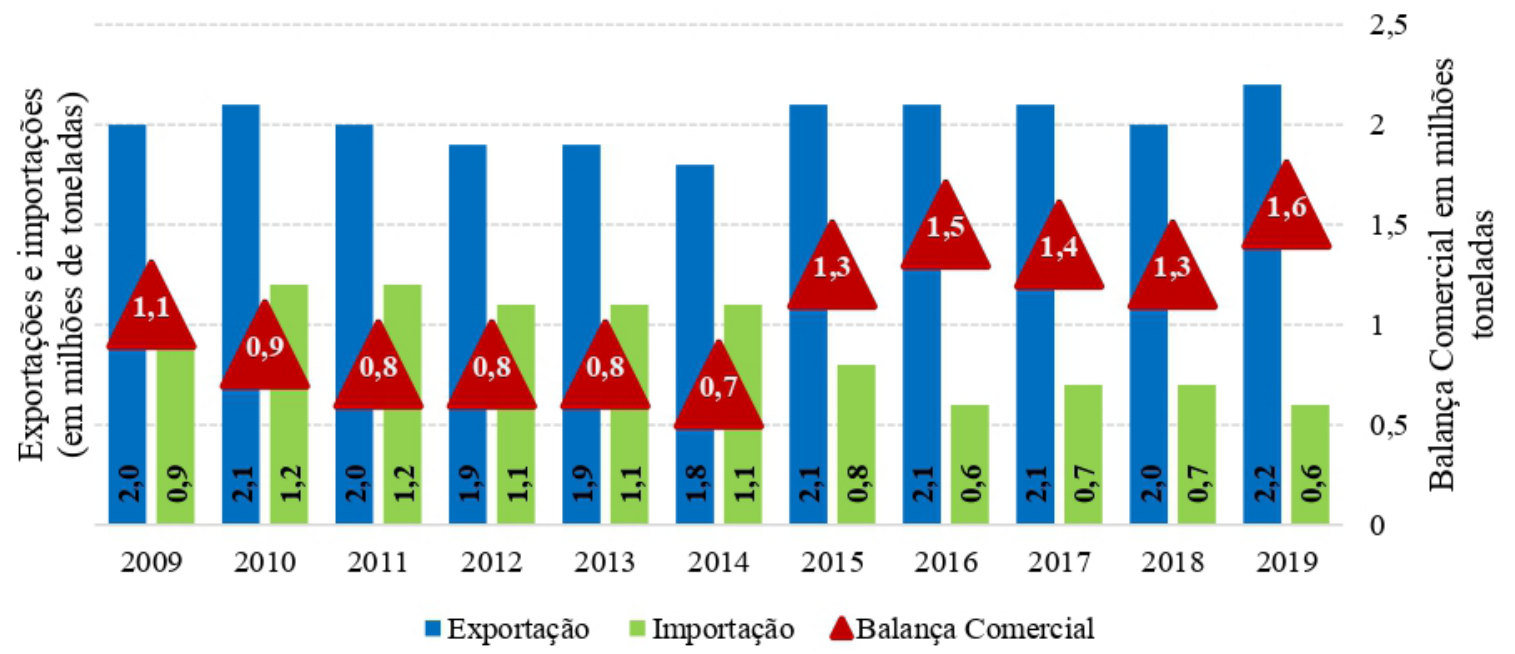

FIGURA 5 - Evolução das exportações e importações de papel no Brasil (em milhões de toneladas) Fonte: Elaborado com base nos dados da IBÁ (2009-2019)

QUADRO 2 - Variáveis utilizadas na análise descritiva e na Decomposição de Oaxaca-Blinder no setor florestal brasileiro

\begin{tabular}{|c|c|c|}
\hline $\begin{array}{l}\text { Código da variável } \\
\text { PNAD }\end{array}$ & Descrição da Variável & $\begin{array}{l}\text { Unidade de } \\
\text { mensuração }\end{array}$ \\
\hline V9058 & $\begin{array}{c}\text { Número de horas trabalhadas por semana no trabalho principal da semana de } \\
\text { referência. }\end{array}$ & Horas/semana \\
\hline V9532 & $\begin{array}{c}\text { Rendimento mensal em dinheiro que recebia normalmente no mês de referência, } \\
\text { no trabalho principal da semana de referência. }\end{array}$ & $\mathrm{R} \$$ \\
\hline V9907 & $\begin{array}{c}\text { Código da atividade (02001 e } 02002 \text { - Silvicultura, exploração florestal e serviços } \\
\text { relacionados com estas atividades, } 20000 \text { - Fabricação de produtos de madeira, } \\
21001 \text { e } 21002 \text { - Fabricação de celulose, papel e produtos de papel, } 22000 \text { - } \\
\text { Edição, impressão e reprodução de gravações). }\end{array}$ & Unidade \\
\hline V8005 & $\begin{array}{l}\text { Idade do morador na data de referência. A característica idade deve ser entendida } \\
\text { como proxy da experiência no mercado de trabalho: quanto mais velho o } \\
\text { trabalhador, supõem-se que mais experiente ele será (Cirino \& De Lima, 2012). }\end{array}$ & Idade em anos \\
\hline V4803 & Anos de estudo. & Anos de estudo \\
\hline V4706 & $\begin{array}{l}\text { Posição na ocupação no trabalho principal da semana de referência para pessoas } \\
\text { de } 10 \text { anos ou mais de idade. }\end{array}$ & Função \\
\hline V0302 & Gênero & Unidade \\
\hline V0404 & Cor ou raça. & Unidade \\
\hline V4808 & $\begin{array}{l}\text { Atividade principal do empreendimento do trabalho principal da semana de } \\
\text { referência para pessoas de cinco anos ou mais de idade. }\end{array}$ & Unidade \\
\hline
\end{tabular}

Fonte: Elaboração própria com base na PNAD (2015)

Organizações Rurais \& Agroindustriais, Lavras, 23:e1633, 2021 
códigos de identificação utilizados do setor florestal brasileiro foram 02001 e 02002 para a silvicultura, exploração florestal e serviços relacionados com estas atividades; 20000 para a fabricação de produtos de madeira; 21001 e 21002 para a fabricação de celulose, papel e produtos de papel; e 22000 para a edição, a impressão e a reprodução de gravações.

Analisou-se o setor florestal brasileiro como um todo e, também, separadamente. A variável V4808 permite identificar a atividade principal do empreendimento, ou seja, se é agrícola ou industrial. O ramo agrícola compreende a atividade de silvicultura, exploração florestal e serviços relacionados a estas atividades, enquanto o ramo industrial abrange as atividades de fabricação de produtos de madeira, fabricação de celulose, papel e produtos de papel, atividades de edição, impressão e reprodução de gravações.

\subsection{Decomposição Oaxaca-Blinder}

De forma a captar uma possível discriminação de gênero e/ou raça/cor no setor, realizou-se a decomposição de Oaxaca-Blinder. Este método consiste em estimar, inicialmente, os rendimentos por hora dos trabalhadores, aqui aplicados ao setor florestal brasileiro, com o propósito de realizar uma posterior decomposição dos diferenciais de rendimento. As equações de rendimento podem ser representadas conforme a expressão abaixo:

$\ln (y)=X^{\prime} \beta+v$

em que $\operatorname{In}(y)$ é o vetor do logaritmo natural do rendimento do trabalhador; $X$ ' $\beta$ é a matriz de variáveis explicativas; e $v$ é o vetor de erros aleatórios (Cirino \& De Lima, 2012).

Como a variável dependente identifica o rendimento do trabalhador, observa-se aqui um problema de seleção amostral na estimação da Equação (1), já que esta variável só pode ser observada para o indivíduo que estiver, de fato, auferindo algum rendimento. Este problema pode ser contornado ao se utilizar o modelo de seleção amostral desenvolvido por Heckman (1979), que propõe estimar uma equação de seleção a qual considere a decisão do indivíduo participar do mercado de trabalho auferindo rendimentos.

Ao identificar, a partir da equação de seleção, a razão inversa de Mills - variável que também deve ser incluída na equação de rendimentos - obtêm-se estimativas consistentes para os parâmetros da equação de rendimentos. Neste estudo, a equação de seleção foi estimada a partir de um modelo probit, que identificou a probabilidade de um indivíduo participar da amostra, ou seja, a probabilidade de estar participando do mercado de trabalho auferindo rendimentos ${ }^{2}$.

Segundo Oaxaca (1973) e Blinder (1973), para calcular a desigualdade salarial existente, por exemplo, entre homens e mulheres, o primeiro passo é a construção de equações mincerianas, como a Equação (1), para cada um dos grupos em questão. As equações têm como variável dependente o logaritmo ${ }^{3}$ do rendimento médio do trabalho principal, e as variáveis independentes consideram características como a idade ${ }^{4}$, raça/cor, posição na ocupação e escolaridade. $\mathrm{O}$ rendimento médio para os homens pode ser escrito como:

$\hat{Y}_{H}=\bar{X}_{H} \hat{\beta}_{H}$

e para as mulheres:

$\hat{Y}_{M}=\bar{X}_{M} \hat{\beta}_{M}$

onde $Y$ é o rendimento médio de cada indivíduo pertencente a cada um dos grupos, e os subscritos $\mathrm{H}$ e $\mathrm{M}$, representam os homens e mulheres, respectivamente. A matriz representa as características médias de cada grupo, e o vetor $\beta$ simboliza o retorno dessas características. Desta forma, por Equações (2) e (3), calcula-se a diferença:

$\hat{Y}_{H}-\hat{Y}_{M}=\bar{X}_{H} \hat{\beta}_{H}-\bar{X}_{M} \hat{\beta}_{M}$

Dando sequência à decomposição, tem-se que:

$\hat{Y}_{H}-\hat{Y}_{M}=\hat{\beta}_{M}\left(\bar{X}_{H}-\bar{X}_{M}\right)+\bar{X}_{M}\left(\hat{\beta}_{H}-\hat{\beta}_{M}\right)+\left(\bar{X}_{H}-\bar{X}_{M}\right)\left(\hat{\beta}_{H}-\hat{\beta}_{M}\right)$

em que:

$\hat{Y}_{H}-\hat{Y}_{M}$ representa a desigualdade total;

$\hat{\beta}_{M}\left(\bar{X}_{H}-\bar{X}_{M}\right)$ consiste no efeito característica (parte da desigualdade atribuída às diferenças nas variáveis explicativas);

${ }^{2}$ As variáveis explicativas utilizadas no modelo de seleção são variáveis utilizadas para identificar a participação do indivíduo no mercado de trabalho. Neste estudo, foram incluídas as seguintes variáveis de controle: escolaridade, idade, condição na família, presença de filhos, e renda dos demais integrantes da família.

${ }^{3}$ Ao estimar uma equação de rendimentos, utiliza-se a forma logarítmica para incorporar a não linearidade na regressão. A não linearidade faz com que os retornos aumentem em uma proporção constante, o que é mais razoável do que em valor absoluto constante. Outro ponto é que essa forma de regressão faz com que se estreite a amplitude dos valores, tornando as estimativas menos sensíveis às observações extremas (outliers).

${ }^{4}$ A característica idade deve ser entendida como uma proxy da experiência no mercado de trabalho. Como colocado por Cirino e De Lima (2012), quanto mais velho o trabalhador, supõe-se que mais experiente ele será. 
$\bar{X}_{M}\left(\hat{\beta}_{H}-\hat{\beta}_{M}\right)$ refere-se ao efeito preço (parte da desigualdade atribuída às diferenças nos $\beta$ 's), que é conhecido na literatura como termo de discriminação; $\mathrm{E}\left(\bar{X}_{H}-\bar{X}_{M}\right)\left(\hat{\beta}_{H}-\hat{\beta}_{M}\right)$ é a interação entre ambos os termos da equação.

A partir da estimativa do efeito preço, objetivouse observar o quanto do diferencial de ganhos salariais entre homens e mulheres, e brancos e não brancos, no setor florestal brasileiro pode ser atribuído ao fator de discriminação no mercado de trabalho. Ademais, realizaram-se estimativas separadamente para os ramos agrícola e industrial do setor florestal.

\section{RESULTADOS E DISCUSSÃO}

\subsection{Descrição dos trabalhadores do setor florestal brasileiro}

Na Tabela 1, apresenta-se uma análise descritiva das características produtivas destes trabalhadores, como educação, idade, posição na ocupação, gênero e cor/raça. Segundo a PNAD (2015), existem 2.252 pessoas no setor florestal brasileiro com idade igual ou superior a 14 anos.

Segundo a amostra estudada, os trabalhadores do setor florestal estudam, em média, 7,96 anos. Ao analisar a escolaridade segundo o gênero, nota-se que as mulheres têm uma maior média de anos de escolaridade, 8,32 anos, enquanto os homens estudam apenas 7,83 anos. Com relação à cor/raça, os trabalhadores considerados brancos estudam um pouco mais (média de 9,20 anos de estudo), enquanto os indivíduos não brancos estudam apenas 7,02 anos, em média. Estas informações vão ao encontro das análises de Lopes, Vosniak, Fiedler \& Inoue (2011) que, em seu estudo sobre o perfil da mão-de-obra utilizada em uma empresa no Norte do estado do Paraná, identificou que cerca de 77,5\% dos trabalhadores não haviam completado o ensino fundamental.

A média de idade dos trabalhadores do setor florestal é de 38,5 anos. Ao se observar a idade segundo o gênero, nota-se uma média de 38,98 anos entre as mulheres, e 38,33 anos entre os homens. Os trabalhadores brancos e não brancos têm, em média, 39 e 38,12 anos, respectivamente.

Ao analisar a composição do setor florestal brasileiro segundo o gênero, observa-se que, dos 2.252 indivíduos que o compõem, 574 são mulheres, correspondendo a $25,49 \%$ do total. Quanto à cor/raça, este setor é composto por aproximadamente 963 trabalhadores brancos, o que corresponde a $42,76 \%$ do total de trabalhadores, sendo que entre estes trabalhadores brancos, $25,65 \%$ são mulheres. Quando observados os trabalhadores não brancos, aproximadamente $25,37 \%$ são mulheres.

A maioria dos trabalhadores do setor florestal brasileiro $(49,68 \%)$ possui carteira de trabalho assinada. O mesmo é observado ao se analisar este setor segundo o gênero e raça/cor: homens, mulheres, brancos e não brancos são, em sua maioria, trabalhadores que atuam com carteira assinada.

$\mathrm{Na}$ Tabela 2, apresenta-se a análise descritiva das características dos trabalhadores do setor florestal ramo agrícola. De acordo com a PNAD (2015), existem 533 pessoas no ramo agrícola do setor florestal brasileiro com idade igual ou superior a 14 anos.

Pode-se verificar que os homens possuem, em média, uma maior escolaridade (5,09 anos), quando comparados às mulheres (3,64 anos). Segundo a raça/cor, os trabalhadores brancos contam com uma média de 6,19 anos de estudo, enquanto os não brancos estudam, em média, apenas 4,03 anos. A baixa escolaridade está presente no ramo agrícola como um todo, o que pode ser associado ao fato de as atividades agrícolas exigirem uma menor qualificação profissional, já que a maior parte do trabalho é manual (Leite, Soares, Nogueira \& Peña, 2012). Ainda de acordo com Britto, Lopes, Drinko e Gonçalves (2015), a necessidade de ingressar no mercado de trabalho, faz com que os trabalhadores agrícolas abandonem os estudos muito cedo.

No ramo agrícola, a média geral de idade é de 39,91 anos: as mulheres têm, em média, 41,60 anos, e os homens 39,21 anos. Quanto aos trabalhadores brancos, sua média de idade é de 41,43 anos, e a média de 39,28 anos é observada entre os trabalhadores não brancos.

O ramo agrícola do setor florestal brasileiro é composto por 377 trabalhadores homens e 156 trabalhadoras mulheres, representando, respectivamente, $70,73 \%$ e $29,27 \%$ do total. O setor também conta com 377 trabalhadores não brancos e 156 trabalhadores brancos. Portanto, este ramo é composto, em sua maioria, por trabalhadores do gênero masculino e por trabalhadores não brancos. O trabalho agrícola exige muito esforço físico, é um serviço de baixo reconhecimento, e oferece severas condições de trabalho, como apontado por Britto et al. (2015). Logo, nota-se que a maioria de seus trabalhadores possui ensino fundamental incompleto, e é composta por homens e não brancos. 
TABELA 1 - Média e desvio padrão (variáveis contínuas) de algumas características dos trabalhadores do setor florestal brasileiro, para o ano de 2015

\begin{tabular}{cccccc}
\hline \multirow{2}{*}{ Variável } & \multirow{2}{*}{ Total } & \multicolumn{2}{c}{ Gênero } & \multicolumn{2}{c}{ Cor ou raça } \\
\cline { 3 - 6 } & & Mulher & Homem & Branco & Não Branco \\
\hline \multirow{2}{*}{ Educação (Anos) } & 7,96 & 8,32 & 7,83 & 9,20 & 7,02 \\
& $(4,25)$ & $(4,71)$ & $(4,07)$ & $(3,94)$ & $(4,23)$ \\
Idade (Anos) & 38,50 & 38,98 & 38,33 & 39,00 & 38,12 \\
Gênero (\%) & $(13,22)$ & $(12,36)$ & $(13,50)$ & $(13,30)$ & $(13,16)$ \\
-Mulher & & & & & \\
-Homem & 25,49 & - & - & 25,65 & 25,37 \\
Cor ou raça (\%) & 74,51 & - & - & 74,35 & 74,63 \\
-Brancos & & & & & \\
-Não Brancos & 42,76 & 43,03 & 42,66 & - & - \\
Posição na ocupação (\%) & 57,24 & 56,96 & 57,33 & - & - \\
-C/ carteira assinada & & & & & \\
-S/ carteira assinada & 49,68 & 43,55 & 51,78 & 55,97 & 44,99 \\
-Conta própria & 16,96 & 8,72 & 19,79 & 13,50 & 19,55 \\
-Empregador & 24,64 & 34,49 & 21,27 & 20,66 & 27,61 \\
- Outros & 4,67 & 2,62 & 5,37 & 8,10 & 2,10 \\
\hline
\end{tabular}

Fonte: Elaboração própria com base nos dados da PNAD (2015)

TABELA 2 - Média e desvio padrão (variáveis contínuas) de algumas características dos trabalhadores do ramo agrícola do setor florestal brasileiro, para o ano de 2015

\begin{tabular}{cccccc}
\hline \multirow{2}{*}{ Variável } & \multirow{2}{*}{ Total } & \multicolumn{2}{c}{ Gênero } & \multicolumn{2}{c}{ Cor ou raça } \\
\cline { 3 - 6 } & & Mulher & Homem & Branco & Não Branco \\
\hline \multirow{2}{*}{ Educação (Anos) } & 4,66 & 3,64 & 5,09 & 6,19 & 4,03 \\
& $(3,80)$ & $(3,55)$ & $(3,83)$ & $(3,92)$ & $(3,57)$ \\
Idade (Anos) & 39,91 & 41,60 & 39,21 & 41,43 & 39,28 \\
Gênero (\%) & $(13,38)$ & $(12,89)$ & $(13,53)$ & $(13,74)$ & $(13,20)$ \\
-Mulher & & & & & \\
-Homem & 29,27 & - & - & 14,11 & 35,55 \\
Cor ou raça (\%) & 70,73 & - & - & 85,89 & 64,45 \\
-Brancos & & & & & \\
-Não Brancos & 29,27 & 14,11 & 35,55 & - & - \\
Posição na ocupação (\%) & 70,73 & 85,89 & 64,45 & - & \\
-C/ carteira assinada & 22,89 & & & & 21,22 \\
-S/ carteira assinada & 28,51 & 5,12 & 30,23 & 26,92 & 27,58 \\
-Conta própria & 33,20 & 5,76 & 37,93 & 30,76 & 0,28 \\
-Empregador & 1,70 & 55,77 & 23,87 & 30,76 & 16,71 \\
- Outros & 13,70 & 0,66 & 2,13 & 5,14 & \\
\hline
\end{tabular}

Fonte: Elaboração própria com base nos dados da PNAD (2015) 
A análise da posição na ocupação dos trabalhadores do ramo agrícola mostra que a maioria dos indivíduos trabalha por conta própria $(33,20 \%)$. Entre as mulheres deste ramo, $55,77 \%$ delas atuam por conta própria, já entre os homens, estes trabalham, em sua maioria, sem carteira assinada (37,93\%), o que reflete o alto nível de informalidade presente neste ramo. Quanto aos trabalhadores brancos, a maioria deles ocupa a posição de trabalhador sem carteira assinada $(30,76 \%)$ e trabalhador por conta própria (30,76\%). Já entre não brancos, a maioria trabalha por conta própria $(34,21 \%)$ (Tabela 2$)$.

Na Tabela 3, apresenta-se a análise descritiva das características produtivas dos trabalhadores do ramo industrial do setor de papel e celulose brasileiro. Segundo dados da PNAD (2015), existem 1,719 pessoas no ramo industrial do setor florestal brasileiro com idade igual ou superior a 14 anos.

Nota-se que as mulheres estudam, em média, 10,07 anos, enquanto os homens estudam apenas 8,63 anos. Já os trabalhadores brancos do setor estudam, em média, 9,79 anos, enquanto os trabalhadores não brancos estudam apenas 8,26 anos.

A média de idade, no ramo industrial, dos trabalhadores em geral é de 38,06 anos, inferior à média de idade geral do setor florestal. As mulheres trabalhadoras deste ramo possuem uma média de idade de 38,01 anos, enquanto os homens têm, em média, 38,07 anos. Para os trabalhadores brancos e não brancos, as médias de idade são, respectivamente, 38,53 e 37,64 anos.

O ramo industrial é composto, em sua maioria, por trabalhadores homens: eles representam $75,68 \%$ dos trabalhadores deste ramo. Seguindo a mesma tendência, os homens são maioria entre os trabalhadores brancos e entre os não brancos, representando $72,12 \%$ e 78,83\% dos trabalhadores, respectivamente.

No ramo industrial, a maioria dos trabalhadores são não brancos $(53,05 \%)$ : entre os homens, a maior parte são não brancos $(55,26 \%)$, já entre as mulheres, a maioria das trabalhadoras são brancas $(53,83 \%)$. Quanto à posição na ocupação, a maior proporção de trabalhadores está no grupo com carteira assinada $(57,99 \%)$, o que demonstra a formalidade do setor. O mesmo é observado quando se analisam os trabalhadores por gênero: $58,03 \%$ dos homens e $57,89 \%$ das mulheres possuem carteira assinada. Na análise por cor/raça não é diferente: $51,58 \%$ dos trabalhadores brancos e $54,82 \%$ dos não brancos possuem registro na carteira de trabalho.

TABELA 3 - Média e desvio padrão (variáveis contínuas) de algumas características dos trabalhadores do ramo industrial do setor florestal brasileiro, para o ano de 2015

\begin{tabular}{cccccc}
\hline \multirow{2}{*}{ Variável } & \multirow{2}{*}{ Total } & \multicolumn{2}{c}{ Gênero } & \multicolumn{2}{c}{ Cor ou raça } \\
\cline { 3 - 6 } & & Mulher & Homem & Branco & Não Branco \\
\hline Educação (Anos) & 8,98 & 10,07 & 8,63 & 9,79 & 8,26 \\
& $(3,84)$ & $(3,82)$ & $(3,79)$ & $(3,67)$ & $(3,85)$ \\
Idade (Anos) & 38,06 & 38,01 & 38,07 & 38,53 & 37,64 \\
Gênero (\%) & $(13,15)$ & $(12,02)$ & $(13,49)$ & $(13,17)$ & $(13,12)$ \\
-Mulher & & & & & \\
-Homem & 24,32 & - & - & 27,88 & 21,17 \\
Cor ou raça (\%) & 75,68 & - & - & 72,12 & 78,83 \\
-Brancos & & & & & \\
-Não Brancos & 46,95 & 53,83 & 44,74 & - & - \\
Posição na ocupação (\%) & 53,05 & 46,17 & 55,26 & - & \\
-C/ carteira assinada & & & & & 54,82 \\
-S/ carteira assinada & 57,99 & 57,89 & 58,03 & 61,58 & 16,22 \\
-Conta própria & 13,37 & 9,80 & 14,52 & 10,16 & 24,89 \\
-Empregador & 21,98 & 26,55 & 20,52 & 18,71 & 2,85 \\
- Outros & 5,58 & 3,36 & 6,30 & 8,67 & 1,22 \\
\hline
\end{tabular}

Fonte: Elaboração própria com base nos dados da PNAD (2015) 
Ao compararmos o ramo agrícola ao ramo industrial, destacam-se diferenças relacionadas à escolaridade: o ramo agrícola conta com uma menor média de escolaridade, 4,66 contra 8,98 anos de estudo. Este resultado pode ser atribuído ao fato de a indústria de celulose utilizar mão de obra mais qualificada, como mencionado por Montebello e Bacha (2011), sendo a atividade industrial mais intensiva em capital, exigindo, assim, maior escolaridade.

As mulheres do setor florestal brasileiro possuem uma maior escolaridade e são mais velhas, o que pode ser entendido como uma maior experiência. Estas características estão associadas a maiores salários, quando comparadas aos homens. Porém, conforme o estudo de Giuberti e Menezes-Filho (2005), a idade das mulheres pode não refletir sua experiência no mercado de trabalho, devido a suas decisões a respeito da maternidade, fato que pode reforçar as diferenças salariais entre homens e mulheres. E quando se trata de raça/cor, pode-se observar que os trabalhadores brancos possuem características produtivas mais favoráveis a maiores salários.

\subsection{Diferencial de rendimento do trabalho entre os trabalhadores do setor florestal brasileiro}

Com o objetivo de realizar a decomposição do diferencial de rendimentos e observar a representatividade de cada efeito no diferencial total, analisaram-se as estimativas das equações de rendimento dos trabalhadores do setor florestal brasileiro de forma a identificar qual a participação da discriminação por gênero e cor/raça na diferença de rendimentos destes grupos.

Na Tabela 4, é apresentada a decomposição da diferença do logaritmo do rendimento/hora entre os trabalhadores homens e mulheres do setor florestal brasileiro. Com base na decomposição de Oaxaca-Blinder, expressa na Equação 5, observa-se que a desigualdade total do setor florestal brasileiro, considerando o gênero, é de 0,3585 . Os resultados mostram que o rendimento/ hora dos trabalhadores do gênero masculino é de R\$ 7,29 , enquanto o rendimento/hora do trabalho feminino é de $\mathrm{R} \$ 5,10$. Isso significa que, na média, o rendimento salarial dos homens é $43,12 \%$ superior ao rendimento salarial das mulheres.

Segundo Jann (2008), o efeito característica obtido na decomposição refere-se à parte da desigualdade atribuída às diferenças nas variáveis explicativas; o efeito preço mede o retorno de cada característica produtiva; e o termo de interação mede o efeito simultâneo das diferenças nas características e diferenças nos retornos salariais.

TABELA 4 - Decomposição da diferença do logaritmo do rendimento/hora entre trabalhadores do setor florestal brasileiro segundo o gênero

\begin{tabular}{|c|c|c|c|c|c|c|}
\hline \multirow{2}{*}{$\begin{array}{l}\text { Diferencial do } \\
\text { Valor esperado } \\
\text { do logaritmo do } \\
\text { rendimento/ hora }\end{array}$} & \multirow[b]{2}{*}{ Coeficiente } & \multirow[b]{2}{*}{$\begin{array}{c}\text { Rendimento } \\
\text { hora }^{1}\end{array}$} & \multicolumn{2}{|c|}{ Agrícola } & \multicolumn{2}{|c|}{ Industrial } \\
\hline & & & Coeficiente & $\begin{array}{c}\text { Rendimento } \\
\text { hora }\end{array}$ & Coeficiente & $\begin{array}{c}\text { Rendimento } \\
\text { hora }\end{array}$ \\
\hline Homens & $\begin{array}{l}1,9870^{*} \\
(0,0204)\end{array}$ & 7,2936 & $\begin{array}{l}1,6236^{*} \\
(0,0484)\end{array}$ & 5,0713 & $\begin{array}{l}2,0882 * \\
(0,0216)\end{array}$ & 8,0704 \\
\hline Mulheres & $\begin{array}{l}1,6285^{*} \\
(0,0509)\end{array}$ & 5,0962 & $\begin{array}{l}0,2902 * \\
(0,0897)\end{array}$ & 1,3367 & $\begin{array}{l}1,9371 * \\
(0,0469)\end{array}$ & 6,9386 \\
\hline Diferença & $\begin{array}{l}0,3585^{*} \\
(0,0548)\end{array}$ & 1,4312 & $\begin{array}{l}1,3333^{*} \\
(0,1019)\end{array}$ & 3,7924 & $\begin{array}{l}0,1510^{*} \\
(0,0516)\end{array}$ & 1,1630 \\
\hline Efeito característica & $\begin{array}{l}-0,0814 \\
(0,0499)\end{array}$ & $\begin{array}{c}\% \text { Diferença } \\
-22,71\end{array}$ & $\begin{array}{l}0,6488^{*} \\
(0,1313)\end{array}$ & $\begin{array}{c}\text { \% Diferença } \\
48,66\end{array}$ & $\begin{array}{c}-0,1625^{*} \\
(0,0436)\end{array}$ & $\begin{array}{c}\text { \% Diferença } \\
-107,62\end{array}$ \\
\hline Efeito preço & $\begin{array}{l}0,4091 * \\
(0,0449)\end{array}$ & 114,11 & $\begin{array}{l}0,9384^{*} \\
(0,1077)\end{array}$ & 70,38 & $\begin{array}{l}0,2561 * \\
(0,0458)\end{array}$ & 169,60 \\
\hline Interação & $\begin{array}{c}0,0307 \\
(0,0374)\end{array}$ & 8,56 & $\begin{array}{c}-0,2539 \\
(0,1385)\end{array}$ & $-19,04$ & $\begin{array}{c}0,0575 \\
(0,0354)\end{array}$ & 38,08 \\
\hline
\end{tabular}

Fonte: Elaboração própria com base nos dados da PNAD 2015

Nota 1: *Significativo a 1\%; **Significativo a 5\%; Nota 2: Variáveis de controle - educação, idade, idade ao quadrado (proxy da experiência), gênero, cor ou raça e posição na ocupação

${ }^{1} \mathrm{O}$ rendimento hora é calculado por meio do antilog (exponencial) do coeficiente 
Como pode ser observado, o efeito característica não é estatisticamente significativo no setor como um todo. Já no ramo agrícola, o efeito característica $(0,6488)$ é significativo a $1 \%$, representando $48,66 \%{ }^{5}$ do diferencial total de rendimentos. Este resultado indica que, caso as trabalhadoras tivessem os mesmos atributos dos trabalhadores homens, elas receberiam aproximadamente $91,3 \%{ }^{6}$ a mais do que elas recebem, equivalente a mais $\mathrm{R} \$ 1,22$ por hora trabalhada.

Enquanto isso, no ramo industrial, o efeito característica $(-0,1625)$ representa uma diminuição do diferencial de rendimentos $(-107,62 \%)$ : o retorno médio do trabalho feminino seria $15 \%$ menor caso as mulheres tivessem as mesmas características observáveis dos homens - o rendimento que é de $\mathrm{R} \$ 6,94 /$ hora cairia para $\mathrm{R} \$ 5,90 /$ hora. O diferencial é, nesse caso, negativo, pois as mulheres têm, por exemplo, um maior nível de escolaridade que os homens (10,1 contra 8,6 anos de escolaridade média), o que é favorável ao setor, pois a indústria é mais intensiva em capital, e por isso demanda mão de obra mais qualificada.

O efeito preço também é o maior responsável pela diferenciação salarial entre homens e mulheres nos ramos agrícola e industrial. No ramo agrícola, o efeito preço $(0,9384)$ representa $70,38 \%$ do diferencial total de rendimentos, indicando que as mulheres teriam rendimentos $155,59 \%$ maiores, caso elas tivessem o mesmo retorno das características observáveis dos homens. Neste caso, o salário médio que é de $\mathrm{R} \$ 1,34$ por hora trabalhada, passaria a ser $\mathrm{R} \$ 3,42$.

Já no ramo industrial, o efeito preço $(0,2561)$ representa $169,60 \%$ do diferencial salarial. Considerando um cenário em que as mulheres tivessem os mesmos coeficientes dos homens, elas teriam ganhos $29,19 \%$ superiores - o rendimento médio, que é de $\mathrm{R} \$ 6,94 /$ hora, aumentaria para $\mathrm{R} \$ 8,96$. O termo de interação não é estatisticamente significativo em nenhuma das análises.

Em suma, os resultados da Tabela 4 mostram que existe um diferencial de rendimentos a favor dos homens no setor florestal brasileiro, e este diferencial é bem mais expressivo no setor agrícola, relativamente ao setor industrial. Além disso, a partir da decomposição, pode-se observar que o efeito preço é o maior responsável pelo diferencial de rendimentos,

${ }^{5} \mathrm{O}$ percentual de diferença é calculado através do respectivo coeficiente dividido pelo coeficiente da diferença.

${ }^{6}$ É calculado por meio do exponencial do coeficiente menos um. contribuindo para aumentar as diferenças entre os gêneros de maneira ainda mais significativa no ramo industrial. Assim, mesmo que os trabalhadores tivessem os mesmos atributos produtivos, as mulheres receberiam rendimentos inferiores ao dos homens, dando indícios de uma possível discriminação de gênero no setor florestal brasileiro.

Na Tabela 5, apresenta-se a decomposição do diferencial salarial dos trabalhadores brancos e não brancos do setor florestal brasileiro. Os resultados mostram que a diferença total do logaritmo do rendimento/hora é de 0,4377 . Os trabalhadores brancos recebem, em média, um salário/hora de $\mathrm{R} \$ 8,60$, enquanto os não brancos recebem $\mathrm{R} \$ 5,55$. Portanto, verifica-se que o rendimento dos trabalhadores brancos é superior ao dos trabalhadores não brancos em 54,91\%.

O efeito característica é o maior responsável pelo diferencial total de rendimentos observados, ou seja, a maior parte da diferença salarial se deve a diferenças nas características produtivas dos trabalhadores. Esse efeito $(0,2414)$, que representa $55,15 \%$ da diferença salarial total, sugere que, caso os trabalhadores não brancos tivessem os mesmos atributos dos trabalhadores brancos, eles receberiam cerca de $27,30 \%$ a mais do que eles, de fato, recebem. Nestas condições, o salário médio dos trabalhadores não brancos seria de $\mathrm{R} \$ 7,07$ por hora trabalhada.

No ramo agrícola, o efeito característica $(0,3342)$ é responsável por $61,20 \%$ da diferenciação salarial entre brancos e não brancos. Essa diferença nas características produtivas faria com que trabalhadores não brancos, caso apresentassem as mesmas características observáveis dos trabalhadores brancos, tivessem seu retorno médio do trabalho aumentado em $39,68 \%$. Ou seja, eles receberiam, em média, $\mathrm{R} \$ 4,53 /$ hora, em vez de $\mathrm{R} \$ 3,24$.

Já no ramo industrial, o efeito decorrente das diferenças nas características $(0,1655)$ é responsável por $49,20 \%$ da diferenciação salarial, indicando que os trabalhadores não brancos receberiam $\mathrm{R} \$ 7,86 /$ hora, em vez de $R \$ 6,66$, caso contassem com os mesmos atributos dos trabalhadores brancos - uma variação positiva de $18 \%$.

Os resultados também apontam, segundo a análise por raça/cor, diferenças no retorno das características produtivas no setor florestal brasileiro, sugerindo haver indícios, ainda que menos expressivos, de uma possível discriminação neste setor. $\mathrm{O}$ efeito preço $(0,1037)$ representa $23,69 \%$ do diferencial salarial total, ou seja, 
TABELA 5 - Decomposição da diferença do Logaritmo do Rendimento/hora entre trabalhadores do setor florestal brasileiro segundo a cor ou raça

\begin{tabular}{|c|c|c|c|c|c|c|}
\hline \multirow{2}{*}{$\begin{array}{l}\text { Diferencial do } \\
\text { Valor esperado } \\
\text { do logaritmo do } \\
\text { rendimento/ hora }\end{array}$} & \multirow[b]{2}{*}{ Coeficiente } & \multirow[b]{2}{*}{$\begin{array}{l}\text { Rendimento } \\
\text { hora }\end{array}$} & \multicolumn{2}{|c|}{ Agrícola } & \multicolumn{2}{|c|}{ Industrial } \\
\hline & & & Coeficiente & $\begin{array}{l}\text { Rendimento } \\
\text { hora }\end{array}$ & Coeficiente & $\begin{array}{l}\text { Rendimento } \\
\text { hora }\end{array}$ \\
\hline Branco & $\begin{array}{l}2,1520^{*} \\
(0,0293)\end{array}$ & 8,6020 & $\begin{array}{l}1,7214^{*} \\
(0,0986)\end{array}$ & 5,5924 & $\begin{array}{l}2,2324^{*} \\
(0,0288)\end{array}$ & 9,3222 \\
\hline Não Branco & $\begin{array}{l}1,7143^{*} \\
(0,0256)\end{array}$ & 5,5528 & $\begin{array}{l}1,1754^{*} \\
(0,0536)\end{array}$ & 3,2394 & $\begin{array}{l}1,8959^{*} \\
(0,0265)\end{array}$ & 6,6585 \\
\hline Diferença & $\begin{array}{c}0,4377^{*} \\
0,0389)\end{array}$ & 1,5491 & $\begin{array}{l}0,5461^{*} \\
(0,1122)\end{array}$ & 1,7265 & $\begin{array}{l}0,3364 * \\
(0,0391)\end{array}$ & 1,3999 \\
\hline Efeito característica & $\begin{array}{c}0,2414 \\
(0,0351)\end{array}$ & $\begin{array}{c}\text { \% Diferença } \\
55,15\end{array}$ & $\begin{array}{l}0,3342^{*} \\
(0,0891)\end{array}$ & $\begin{array}{c}\% \text { Diferença } \\
61,20\end{array}$ & $\begin{array}{c}0,1655^{*} \\
(0,0354)\end{array}$ & $\begin{array}{c}\% \text { Diferença } \\
49,20\end{array}$ \\
\hline Efeito preço & $\begin{array}{c}0,1037 * * \\
(0,0450)\end{array}$ & 23,69 & $\begin{array}{l}-0,0185 \\
(0,1141)\end{array}$ & $-3,39$ & $\begin{array}{c}0,0924 \\
(0,0465)\end{array}$ & 27,47 \\
\hline Interação & $\begin{array}{c}0,0926 * * \\
(0,0422)\end{array}$ & 21,16 & $\begin{array}{c}0,2303 * * \\
(0,1140)\end{array}$ & 42,17 & $\begin{array}{c}0,0786 \\
(0,0440) \\
\end{array}$ & 23,37 \\
\hline
\end{tabular}

Fonte: Elaboração própria com base nos dados da PNAD (2015). Nota 1: *Significativo a 1\%; **Significativo a 5\%; Nota 2: Variáveis de controle - educação, idade, idade ao quadrado (proxy da experiência), gênero, raça/cor e posição na ocupação

considerando que os trabalhadores não brancos recebessem o mesmo que os brancos por seus atributos produtivos, eles teriam ganhos 10,93\% superiores. Nos ramos agrícola e industrial, o efeito preço não é estatisticamente significativo.

Com relação ao termo de interação, este é significativo a $5 \%$ para o setor como um todo, e também para o ramo agrícola. O termo representa, por exemplo, um aumento no diferencial total de $21,16 \%$ para o setor florestal brasileiro.

Em resumo, os resultados da Tabela 5 apontam para um diferencial de rendimentos a favor dos trabalhadores brancos no setor florestal brasileiro, e este diferencial é maior no setor agrícola, relativamente ao setor industrial. Ao realizar a decomposição dos diferenciais salariais, nota-se que o efeito característica é o maior responsável pela diferença observada: o fato de os trabalhadores brancos apresentarem rendimentos superiores aos trabalhadores não brancos pode ser explicado, em sua maior parte, pelas diferenças nas características produtivas dos trabalhadores do setor.

A síntese dos resultados, tanto em valores percentuais, como em termos absolutos, está apresentada na Tabela 6. Como evidenciado na análise descritiva, o setor florestal brasileiro é composto, em sua maioria, por trabalhadores homens, o que pode ser explicado tanto por um menor interesse de mulheres pelo setor, como também por um menor interesse dos empregadores do setor em contratar mulheres.

A diferente distribuição entre os gêneros quanto à posição na ocupação dos trabalhadores reforça a afirmação anterior: enquanto a proporção de "Empregadores" do gênero masculino é o dobro do feminino, a proporção de mulheres que ocupa a posição de "Conta própria" e "Outros" é bem superior à proporção de homens. E ainda que homens e mulheres tivessem a mesma posição na ocupação, ainda assim eles poderiam estar atuando em atividades complementarmente diferentes, atividades que tivessem retornos de rendimentos diferentes, o que poderia explicar o maior retorno observado das características produtivas dos homens (efeito preço).

Quando analisados os ramos separadamente, o setor agrícola apresentou um diferencial de rendimentos entre homens e mulheres bem superior ao observado no ramo industrial. Este resultado pode estar refletindo as diferenças nas características observáveis. No setor agrícola, por exemplo, as mulheres contam com um menor nível de escolaridade média que os homens. E a grande maioria delas, ocupa a posição de "Conta própria" e "Outros", enquanto os homens, em sua maioria, se encontram na posição "Com carteira assinada" e "Sem carteira assinada". Já no ramo industrial, as mulheres apresentam um maior nível de escolaridade e a 
distribuição da posição na ocupação é bem mais parecida entre os gêneros.

Ao observar a contribuição do efeito preço para o diferencial total de rendimentos, o efeito preço superou o efeito característica em ambos os ramos do setor florestal. Todavia, a contribuição é mais significante no ramo industrial, o que mais uma vez pode estar refletindo uma participação de homens e mulheres em atividades diferentes no ramo industrial, ainda que ambos ocupem a mesma posição na ocupação. De acordo com Mello (2010), isso pode ocorrer em virtude de alguns setores restringirem a entrada do trabalho feminino decorrente da necessidade de utilizarem a força física na sua execução. E esse pode ser o caso do ramo industrial no setor florestal.

Este estudo confirma os dados apresentados em trabalhos anteriores, como Prestes e Bezerra (2019), Jacinto (2005) e Gomes e Souza (2018), em que se percebe que a desigualdade salarial está presente na sociedade como um todo e na maioria das vezes em favor dos homens.

Diferentemente da análise por gênero, na análise por raça/cor o que chama mais atenção é a contribuição do efeito característica para a explicação do diferencial total de rendimentos. O setor florestal brasileiro é composto em sua maioria por trabalhadores não brancos, mas o fato de os trabalhadores brancos contarem com melhores níveis educacionais e maior experiência (dado sua maior idade média) pode estar explicando esses resultados. Além disso, há uma maior proporção de trabalhadores brancos com carteira assinada, e também uma maior proporção de empregadores brancos, o que também pode explicar esse diferencial de rendimento em favor dos trabalhadores brancos.

TABELA 6 - Síntese da decomposição do diferencial de rendimentos entre trabalhadores do setor florestal brasileiro por gênero e cor/raça - valores absolutos e percentuais

\begin{tabular}{|c|c|c|c|}
\hline Decomposição do diferencial de rendimentos & Setor Florestal & Ramo Agrícola & Ramo Industrial \\
\hline Diferencial de rendimentos por gênero & 0,3585 & 1,3333 & 0,1510 \\
\hline Efeito característica & NS & 0,6488 & $-0,1625$ \\
\hline $\begin{array}{l}\text { Rendimento/hora dos não brancos caso tivessem as características } \\
\text { produtivas dos brancos }(a)\end{array}$ & - & 2,557 & 5,898 \\
\hline Rendimento/hora das mulheres $(b)$ & _- & 1,337 & 6,939 \\
\hline Variação percentual $[(a / b)-1]$ & _- & $91,3 \%$ & $-15 \%$ \\
\hline Efeito preço & 0,4091 & 0,9384 & 0,2561 \\
\hline $\begin{array}{l}\text { Rendimento/hora das mulheres caso tivessem os retornos das } \\
\text { características produtivas dos homens }(a)\end{array}$ & 7,6722 & 3,4164 & 8,9630 \\
\hline Rendimento/hora das mulheres $(b)$ & 5,0962 & 1,3367 & 6,9386 \\
\hline Variação percentual $[(a / b)-1]$ & $50,6 \%$ & $155,6 \%$ & $29,2 \%$ \\
\hline Diferencial de rendimentos por cor/raça & 0,4377 & 0,5461 & 0,3364 \\
\hline Efeito característica & 0,2414 & 0,3342 & 0,1655 \\
\hline $\begin{array}{l}\text { Rendimento/hora dos não brancos caso tivessem as características } \\
\text { produtivas dos brancos }(a)\end{array}$ & 7,0687 & 4,5249 & 7,8570 \\
\hline Rendimento/hora dos não brancos $(b)$ & 5,5528 & 3,2394 & 6,6585 \\
\hline Variação percentual $[(a / b)-1]$ & $27,3 \%$ & $39,7 \%$ & $18,0 \%$ \\
\hline Efeito preço & 0,1037 & NS & NS \\
\hline $\begin{array}{l}\text { Rendimento/hora dos não brancos caso tivessem os retornos das } \\
\text { características produtivas dos brancos }(a)\end{array}$ & 6,1595 & - & - \\
\hline Rendimento/hora dos não brancos $(b)$ & 5,5528 & - & - \\
\hline Variação percentual $[(a / b)-1]$ & $10,93 \%$ & - & - \\
\hline
\end{tabular}

Fonte: Elaboração própria com base nos dados da PNAD (2015); Nota 1: NS= estatisticamente não significativo 


\section{CONCLUSÕES}

Este estudo teve como objetivo analisar a existência de discriminação salarial de gênero e raça/ cor no setor florestal brasileiro, mais especificamente entre os ramos agrícola e industrial deste setor. Para tanto, utilizou-se a decomposição de Oaxaca-Blinder para decompor os diferenciais de salariais estimados por hora de trabalho.

Os resultados encontrados apontaram evidências de discriminação salarial no setor florestal brasileiro como um todo. No entanto, essa possível discriminação se mostrou mais significativa na análise segundo o gênero, relativamente à análise por cor/raça. Neste caso, o efeito preço (discriminação) foi o maior responsável pelo diferencial de salários do setor: tanto no ramo industrial, como no ramo agrícola, o diferencial de rendimento entre os gêneros foi mais explicado por diferenças nos retornos das características produtivas (coeficientes) do que por diferença nas características produtivas (variáveis explicativas).

Dessa forma, de acordo com o efeito preço, se homens e mulheres tivessem exatamente as mesmas características produtivas, ainda assim os homens ganhariam mais do que as mulheres. E este diferencial de rendimentos pode ser decorrente tanto de uma possível discriminação no setor (já que é uma parte do diferencial que não é explicada por diferenças nas características observáveis), como pode ser devido a características que não são possíveis de se observar, e que não estão contempladas na análise, como a produtividade, motivação, habilidade do trabalhador, ou seja características subjetivas difícil de serem mensuradas. Além disso, os próprios trabalhadores fazem escolhas no mercado de trabalho, e homens e mulheres poderiam optar, por exemplo, por postos de trabalho diferentes. E estas escolhas, que não podem ser observadas nos dados, também limitam a identificação do fator discriminação compreendido no efeito preço.

Este estudo vem fortalecer o leque de discussão a respeito da desigualdade salarial existente entre homens/ mulheres e brancos/não brancos que, infelizmente, ainda persistem na maioria das sociedades. Porém, estas situações poderiam ser mitigadas ou eliminadas a partir de políticas públicas que incentivem as empresas a remunerar de forma igualitária as características produtivas, independentemente do gênero ou raça/cor do trabalhador. Não é uma questão de criar quotas para grupos, ou igualar salários de forma estrita, mas sim de remunerar trabalhadores igualmente produtivos de forma igualitária.
Assim, a partir das estimativas feitas nesse trabalho, tem-se a percepção da existência de discriminação de gênero ou cor/raça, com relação aos rendimentos do trabalho no setor florestal brasileiro. Esses indícios de discriminação podem contribuir para orientar as ações do setor na superação das desigualdades sociais entre homens e mulheres e entre brancos e não brancos de modo a promover a justiça social.

\section{AGRADECIMENTO}

Os autores agradecem ao programa de Pós Graduação em Agronegócios da Universidade Federal da Grande Dourados pelo apoio e suporte durante a elaboração desse trabalho

\section{CONFLITO DE INTERESSES}

Não houve conflitos de interesse no assunto ou nos materiais discutidos neste manuscrito.

\section{REFERÊNCIAS}

Associação Mineira do Meio Ambiente. (2018). Recuperado em 15 de agosto de 2018, de http://www. amda.org.br/?string=interna-projetos\& $\operatorname{cod}=31$

Batista, N. N. F., \& Cacciamali, M. C. (2009). Diferencial de salários entre homens e mulheres segundo a condição de migração. Revista Brasileira de Estudos de População, 26(1), 97-115.

Blinder, A. S. (1973). Wage discrimination: reduced form and structural variables. Journal of Human Resources, $8(4), 436-455$.

Böheim, R., Himpele, K., Mahringer, H., \& Zulehner, C. (2013). The distribution of the gender wage gap in Austria: evidence from matched employer-employee data and tax records. Journal for Labour Market Research, 46(1), 19-34.

Bonini, P., \& Pozzobon, F. (2016). Discriminação Salarial Feminina e o Prêmio Salarial de TI na Indústria de Tecnologia da Região Sul. Análise Econômica, 34(66).

Britto, P. C., Lopes, E. D. S., Drinko, C. H. F., \& Gonçalves, S. B. (2015). Fatores humanos e condições de trabalho em atividades de implantação e manutenção florestal. Floresta e ambiente, 22(4), 503-511. 
Cirino, J. F., \& Lima, J. E. D. (2012). Diferenças de rendimento entre as regiões metropolitanas de Belo Horizonte e Salvador: uma discussão a partir da decomposição de Oaxaca-Blinder. Revista Econômica do Nordeste, 43(2), 371-389.

Coleman, M. G. (2003). Job skill and black male wage discrimination. Social Science Quarterly, 84(4), 892906.

de Souza, S. D. C. I., Maia, K., Fiuza-Moura, F. K., Gomes, M. R., \& da Silva, R. J. (2015). Diferenças salariais por gênero e cor e o impacto da discriminação econômica. Revista Brasileira de Estudos Regionais e Urbanos, 9(1), 32-49.

Departamento de Pesquisas e Estudos Econômicos. (2018). Papel e Celulose. Recuperado em 4 de abril de 2018, de https://www.economiaemdia.com.br/EconomiaEmDia/ pdf/infset_papel_e_celulose.pdf

Fonseca, M. R., Bacchi, M. D., Catelan, D. W., Hayashi, P. A., \& Maia, K. (2017). Diferenças salariais e discriminação por gênero e cor na região norte do Brasil. Revista de Políticas Públicas, 21(2), 739-759.

Giuberti, A. C., \& Menezes-Filho, N. (2005). Discriminação de rendimentos por gênero: uma comparação entre o Brasil e os Estados Unidos. Economia Aplicada, 9(3), 369-384.

Gomes, M. R., \& Souza, S. D. C. I. D. (2018). Assimetrias salariais de gênero e a abordagem regional no brasil: uma análise segundo a admissão no emprego e setores de atividade. Revista de Economia Contemporânea, 22(3).

Grandner, T., \& Gstach, D. (2015). Decomposing wage discrimination in Germany and Austria with counterfactual densities. Empirica, 42(1), 49-76.

Heckman, J. J. (1979). Sample selection bias as a specification error. Econometrica: Journal of the econometric society, 153-161.

Instituto Brasileiro de Geografia e Estatística. (2015). Pesquisa Nacional por Amostra de Domicílios (PNAD) - microdados 2015. Recuperado em 03 de abril de 2021, de <http://www.ibge.gov.br/home/estatistica/pesquisas/ pesquisa_resultados .php?id_pesquisa $=40$
Indústria Brasileira de Árvores. (2020). Relatório IBÁ 2020. Recuperado em 13 de maio de 2021, de https://iba. org/datafiles/publicacoes/relatorios/relatorio-iba-2020. pdf

Indústria Brasileira de Árvores. (2018). Relatório IBÁ 2018. Recuperado em 13 de maio de 2021, de https://iba. org/datafiles/publicacoes/relatorios/relatorio-iba-2018. pdf

Jacinto, P. D. A. (2005). Diferenciais de salários por gênero na indústria avícola da região Sul do Brasil: uma análise com micro dados. Revista de Economia e Sociologia Rural, 43(3), 529-555.

Jann, B. (2008). A Stata implementation of the BlinderOaxaca decomposition. Stata Journal, 8(4), 453-479.

Leite, A. M. P., Soares, T. S., Nogueira, G. S., \& Peña, S. V. (2012). Perfil e qualidade de vida de trabalhadores de colheita florestal. Revista Árvore, 36(1), 161-168.

Lopes, E. S., Vosniak, J., Fiedler, N. C., \& Inoue, M. T. (2011). Análise dos fatores humanos e condições de trabalho em operações de implantação florestal. FLORESTA, 41(4).

Mattei, T. F., \& Baço, F. M. B. (2016). Análise da existência de discriminação salarial entre homens e mulheres na indústria de transformação do estado de Santa Catarina. Economia \& Gestão, 16(45), 103-125.

Mattei, T. F., \& Baço, F. M. B. (2017). Análise das desigualdades salariais entre homens e mulheres no mercado de trabalho de Santa Catarina. DRdDesenvolvimento Regional em debate, 7(2), 96-117.

Mello, L. G. (2010, agosto). A complexa teia de desigualdade racial e de gênero no mercado de trabalho brasileiro. In Fazendo Gênero 9 - Diásporas, Diversidades, Deslocamentos, Florianópolis.

Montebello, A. E. S., \& Bacha, C. J. C. (2011). O setor de celulose e papel na economia brasileira. O Papel, 72(4), 47-50.

Oaxaca, R. (1973). Male-female wage differentials in urban labor markets. International Economic Review, 14(3), 693-709. 
Organização Internacional do Trabalho. (1999). Declaração da OIT sobre os princípios e direitos fundamentais no trabalho. Recuperado em 01 de março de 2019, de https:/www.ilo.org/public/english/standards/declaration/ declaration_portuguese.pdf

Organização Internacional do Trabalho. (2011). Igualdade no trabalho: um desafio contínuo. Recuperado em 01 de novembro de 2018, de http://cite.gov.pt/pt/destaques/ complementosDestqs/Relatorio_igualdade.pdf

Organização Internacional do Trabalho. (2018). Plano Nacional de Trabalho Decente: Gerar Trabalho Decente para Combater a Pobreza e as Desigualdades Sociais. Recuperado em 05 de novembro de 2018, de https://www. ilo.org/wcmsp5/groups/public/---americas/---ro-lima/--ilo-brasilia/documents/publication/wcms_226249.pdf
Organização Internacional do Trabalho. (2019). Não discriminação. Recuperado em 05 de março de 2019, de https://www.ilo.org/brasilia/temas/g\%C3\%AAnero-era $\% \mathrm{C} 3 \% \mathrm{~A} 7 \mathrm{a} /$ lang--pt/index.htm

Organização das Nações Unidas. (2014). The Millennium Development Goals Report 2014. Recuperado em 20 de maio de 2021, de http://www.un.org/millenniumgoals/2014\%20 MDG\%20report/MDG\%202014\%20English\%20web.pdf

Prestes, A. F., \& Bezerra, F. M. (2019). Desigualdade salarial entre gêneros: análise por setor e região do Paraná. Economia \& Região, 7(2), 29-45.

Sistema Nacional de Informações Florestais. (2020). Cadeia Produtiva. Recuperado em 23 de maio de 2021, de https://snif.florestal.gov.br/pt-br/cadeia-produtiva 